Assiut Scientific Nursing Journal

http://asnj.journals.ekb.eg

http://www.arabimpactfactor.com

DOI: $10.21608 /$ ASNJ.2021.75594.1175

\title{
Effect of Nursing Instructions on patient's knowledge and Potential Postoperative Complications after Transurethral Resection of the Prostate
}

\author{
Ayat Sayed Khalil ${ }^{1}$, Samia Youssef Sayed ${ }^{2}$, Wafaa Ramadan Ahmed ${ }^{3}$ \& Rabea Ahmed Gadelkareem ${ }^{4}$ \\ ${ }^{1 .}$ Bachelor's degree, Medical Surgical Nursing Department, Faculty of Nursing, Assiut University, Egypt. \\ 2. Assistant Professor of Medical Surgical Nursing, Faculty of Nursing, Assiut University, Egypt. \\ ${ }^{3 .}$ Lecturer of Medical Surgical Nursing, Faculty of Nursing, Assiut University, Egypt. \\ 4. Assistant Professor of Urology, Assiut Urology \& Nephrology Hospital, Faculty of Medicine, Assiut University, Egypt.
}

\begin{abstract}
:
Background: Transurethral resection of the prostate (TURP) consider the golden treatment of benign prostatic hyperplasia (BPH). Aims: To evaluate the effect of pre-operative nursing instructions on the potential post-operative complications after TURP. Study design: A quasi-experimental research design (study-control) was utilized. Setting: Assiut Urology and Nephrology Hospital, Assiut University. Subjects: Eighty male patients undergoing TURP. Tools: Two tools were utilized for data collections including the following: Tool I: Patient assessment sheet: it contained demographic data, pre-operative clinical data, and assessment of postoperative complications. Tool II: Patient's knowledge questionnaire. Results: the age of the majority of the patients in both study and control groups (95\% and $92.5 \%$ respectively) and was between 50-65years old for study and control groups. The main pre-operative symptoms were terminal dribbling and inability to empty the bladder ( $75 \%$ and $67.5 \%$ ) among the study group and (72.5\% and $70 \%$ respectively). A significant differences between both groups regarding the total knowledge and postoperative complications $(P=0.001 *$ and $r .=-0.720)$. Conclusions: Pre-operative nursing instructions improve patients' knowledge and reduce the rates of TURP complications Recommendations: Routine use of pre-operative nursing instructions for patients undergoing TURP.
\end{abstract}

\section{Keywords: Pre-operative nursing instructions, Postoperative complication, \& TURP.}

\section{Introduction:}

Benign prostatic hyperplasia (BPH) means a noncancerous and non-inflammatory enlargement of the prostate gland that leads to urinary obstruction manifests as a weak stream, intermittency, hesitancy, terminal dribbling, urinary frequency, urgency, nocturia, and urge incontinence (Scardino \& Kelman, 2010).

Benign prostate hyperplasia (BPH) is the most common disease among aging males. It is reported that $\mathrm{BPH}$ occurs in $15 \%$ to $60 \%$ of men aged more than 40 years and the prevalence of BPH increases after the age of 40 years, with a prevalence of $8 \%$ $60 \%$ at age 90 years. Some data have suggested that there is decreased risk among Asians compared to the western white population. Genetics, diet, and lifestyle may play a role here. Recent reports suggest the strong relationship of clinical BPH with metabolic syndrome and erectile dysfunction, as well as the possible role of inflammation as a cause of prostatic hyperplasia. Lifestyle changes including exercise and diet are important strategies in controlling this common ailment (D'Ancona et al., 2019).

Transurethral resection of the prostate (TURP) considers the golden treatment of benign prostatic hyperplasia (BPH). Acute and chronic urinary retention, hematuria, urinary bladder stones, recurrent urinary tract infections, and renal insufficiency are complications of (TURP). (Chughtai et al., 2016). It is reserved for men with moderate-to-severe bladder outlet obstruction according to international prostate symptom score (IPSS) and those with complications and failed medical treatment (Urological Sciences Research Foundation, 2011; Cantlay \& Ni Raghallaigh, 2015).

TURP like other surgeries has some postoperative complications such as hemorrhage, bladder discomfort, urinary tract infections, urinary catheter obstruction, and fibrotic scarring. TURP syndrome is fluid overload resulting in disturbed electrolyte balance and hyponatremia due to excess fluid absorption TURP requires hospitalization for three to four days. During this duration, nurses play a crucial role in preventing potential post-operative complications by providing intensive perioperative counseling and education (Martin-Plank, 2018).

So, the medical and nursing staff should pay proper attention to the patient's preparation including cardiovascular, respiratory, hepatic, and neurologic systems before TURP. Post-operative nursing practices involve assessing the urinary catheter and vital signs for early detection of any abnormalities (Silva-Smith, 2017). 
Patients undergoing TURP need self-care training and guideline instructions to manage and control the postoperative symptoms and complications (Kassouf et al., 2016). Also, providing the patient the proper instructions about self-care, activities, exercises, nutrition and hygienic care all are very important nursing practices before discharge (Moschini et al., 2019).

\section{Significance of the study:}

The flow rate during 2018 was 110 according to Assiut University Hospital statistical record, (2018).it was found that most patients undergoing TURP are prone to postoperative complications due to a lack of knowledge regarding the procedure, thus they need special nursing instructions to minimize these complications. This study aiming to assess the effect of pre-operative nursing instructions on potential postoperative complications of TURP.

Aim of the study:

To evaluate the effect of pre-operative nursing instructions on the patient's knowledge and potential post-operative complications of TURP.

Hypotheses:

To fulfill the aim of the study the following research hypotheses will be formulated:

- The post means the knowledge score of the study group who receive the pre-operative nursing instructions will be higher than that of the control group.

- Potential Post-operative complications of TURP will be reduced in patients who receive the preoperative nursing instructions.

Operational definition:

Pre-operative nursing instruction :

It is the preparation and management of patients before surgery. It includes both physical and psychological preparation. It includes instruction about the preoperative period, the surgical procedures, and the postoperative period (Levett et al. 2016)

Potential postoperative complications:

It is an "after-effect" of surgery that is inherent to the procedure, as any deviation from the normal postoperative course (Mamoulakis et al., 2011).

\section{Patients and Methods: \\ Research design:}

A quasi-experimental research design (including study and control groups) was utilized to conduct this study.

It is experimental research but missing, the random assignment and/or the control groups. So, it is most common to be applied in nursing researchers
Study setting:

Setting in Assiut Urology and Nephrology Hospital, Assiut University, Assiut, Egypt during the period from November 2019 to October 2020.

\section{Study sample:}

A purposive sample of 80 patients with $\mathrm{BPH}$ undergoing TURP. Their age ranged from 40-65years old. They were equally divided into two groups (study\& control).

Exclusion criteria:

- Patients, who were not able to receive, understand or respond to instructions.

- Patients who had an open prostatectomy.

- A patient who had unsuccessful TURP.

- Patients who had concomitant procedures other than TURP.

- Patients who had TURP for other causes than BPH.

- Patients with an education level higher than the basic level.

Sample size:

- The sample was selected by using the following equation according to Steven, ( 2012) :

$$
n=\frac{N \times p(1-p)}{\left.\left.\llbracket N-1 \times\left(d^{2} \div z^{2}\right)\right]+p(1-p)\right]}
$$

- Sample size $=80$ patients

- $\mathbf{N}=$ total patient population size is 110 who admitted for TURP in Assiut Urology and Nephrology Hospital at Assiut University hospitals during the year

$\bullet \mathbf{z}=$ confidence levels are 0.95 and are equal to 1.96

$\bullet \mathbf{d}=$ The error ratio $=0.05$

- $\mathbf{P}=$ The property availability ratio and neutral $=0.50$

Tools of data collection:

Tool I: Patient assessment questionnaire:

This tool aimed to assess patient's demographic data, preoperative clinical data, intraoperative data, and postoperative data. It composed of four parts:

Part 1: Demographic data:

patient name, age, sex, level of education, marital status, and occupation.

Part 2: Preoperative clinical data:

This part comprised; BPH signs and symptoms, medical diagnosis, associated comorbidities, and length of hospital stay. This part represented the baseline of the patient's characteristics and their medical conditions.

Part 3: Assessment of post-operative complications:

This part included the postoperative complications which were classified according to Modified ClavienDindo classification (Mamoulakis et al., 2011). The complications included hemorrhage, urinary tract infections, urinary retention, weak urinary stream, 
and urinary incontinence. This part included the data from patients and follow-up for three months after TURP surgery.

\section{Tool II: Patient's knowledge questionnaire:}

This questionnaire developed by the researchers based on their observations and literature review. It aimed to assess the patient's knowledge covering the information that should be relevant to the topic (definition of TURP\& BPH, indications of TURP, preoperative preparations, nursing instructions related to exercises, nutrition, and hygienic care, and potential postoperative complications. It consisted of twenty questions; 10 multiple choice questions and 10 true and false questions. It was used before the implementation of the nursing instructions for both groups (study and control). The same tool was used immediately after the implementation of the nursing instruction (immediate post-test) to evaluate the gain in knowledge level after the intervention only for the study group.

\section{Scoring system for this questionnaire:}

Each correct answer was given 1 degree and each wrong answer $=$ zero degrees.

The total score $=20$ degrees. The maximum score limit was 20 degrees and its minimal limit was zero. Patients with less than $50 \%$ have a poor level of knowledge, those with $50-75 \%$ had a fair level of knowledge, and those who obtained more than $75 \%$ have a satisfactory knowledge level.

\section{Methods:}

The study was carried out in three phases:

Phase (1): Preparatory phase:

Administrative approval: An official permission was obtained from the head of the Urology Department / Assiut Urology and Nephrology Hospital, Assuit University.

\section{Ethical considerations:}

The research proposal was approved by the Ethical Committee in the Faculty of Nursing, Assiut University. There was no risk for patients during the application of the research tool. The study followed the common ethical principles in clinical research, according to the declaration of Helsinki (World Medical Association, 2013). Oral consent was obtained from patients after explaining the nature and purpose of the study. Confidentiality and anonymity were assured. The study patient had the right to refuse to participate and/or withdraw from the study without any rationale at any time. Study patient privacy was considered during the collection of data. Official permission was obtained from the Dean of Faculty of Nursing, Assiut University, and the chairman of the Urology Department, Assiut University.

Validity and Reliability of the study tools:

The tools were tested for content validity by five experts of academic medical and nursing staff from the Faculty of Nursing at Assiut University. No modifications were needed and then the tools were designed in their final format. The reliability was measured using the Cronbach test. The tools were proved to be reliable $(0.73)$.

Pilot study: A pilot study was conducted on ten percent of the study sample (8patients) in a selected setting to evaluate the applicability \& clarity of the tools. According to this pilot study, the required modifications were made. Those patients who were involved in the pilot study were included in the study total sample.

Phase (2): Implementation phase:

The study data were collected from the Urology department/Urology and Nephrology Hospital, Assuit University from November 2019 to October 2020.

Patients were approached individually to explain the purpose and the nature of the study and to obtain their written consent for participation.

Both study and control groups of patients were assessed for their demographic data, pre-operative clinical data, assessment of post-operative data, and Patient knowledge questionnaire. (Tool I and II) was measured.

Pre-operative nursing instructions:

It was developed by the researcher based on patients' identified needs to post the pre-assessment in a simple Arabic language and supplied with illustrated photos aiming to help the patient to understand the content. Pre-operative nursing instructions about TURP consisted of eight sections. First: the anatomy and function of the prostate. Second: Definition of TURP and its indications. Third: Advantages of TURP. Fourth: preparation before the operation according to the stander level. Fifth: The procedure of TURP. Sixth: Expected postoperative complications. Seventh: Nursing care information after TURP as; nutrition, drinking fluids needed, exercise, and urinary catheter care. Eighth: Indications of seeking medical advice.

- The study group received the pre-operative nursing instructions about TURP through teaching sessions.

- The Control group received the routine verbal instruction after TURB only.

- Pre-operative nursing instruction was given to the study group preoperatively the day before the surgery.

- The patients in the study group were taught individually to be oriented about the objectives of the pre-operative nursing instructions. Short interactive discussions and demonstrations supported by illustrated pictures were shown for all patients.

- Every session lasted for about 30 minutes; one session was produced on the first day of admission. Maximum 2 sessions were given daily. 
- Constant feedback was assured at the end of every session to clear any misunderstandings.

- Each patient received a hard copy of the preoperative nursing instructions during the preoperative period.

Phase (3): Evaluation phase:

- Knowledge of the study group was evaluated by post-test after application of the pre-operative nursing instructions using (Tool I, part 3and Tool II).

- After three months of the pre-operative nursing instructions application, the researcher assessed patients' postoperative complications using (part 3 of tool I).

\section{Statistical design:}

It is done by using the computer program SPSS" version. 20" Chicago, USA. The result presented as mean \pm , standard deviation or number and percentage. T-test used to significance for the numerical variables. Chi-square was used to non-parametric variables.

\section{Results:}

Table (1): Frequency distribution of Socio-demographic characteristics and medical data of study and control groups (N.80).

\begin{tabular}{|c|c|c|c|}
\hline Variables & $\begin{array}{c}\text { Study group } \\
\text { N. }=\mathbf{4 0}(\%)\end{array}$ & $\begin{array}{c}\text { Control group } \\
\text { N. }=\mathbf{4 0}(\%)\end{array}$ & p-value \\
\hline \multicolumn{3}{|l|}{ Age group } & \multirow{4}{*}{0.284} \\
\hline $40-50$ years & $2(5 \%)$ & $3(7.5 \%)$ & \\
\hline 50- 65 years & $38(95 \%)$ & $37(92.5 \%)$ & \\
\hline Mean \pm SD & $51 \pm 12.8$ & $50 \pm 10.7$ & \\
\hline \multicolumn{3}{|l|}{ Marital status } & \multirow{5}{*}{0.268} \\
\hline Single & $2(5 \%)$ & $0(0 \%)$ & \\
\hline Married & $27(67.5 \%)$ & $33(82.5)$ & \\
\hline Divorced & $3(7.5 \%)$ & $3(7.5 \%)$ & \\
\hline Widow & $8(20 \%)$ & $4(10 \%)$ & \\
\hline \multicolumn{3}{|l|}{ Level of education } & \multirow{4}{*}{0.783} \\
\hline Illiterate & $12(30 \%)$ & $12(30 \%)$ & \\
\hline Read and write & $22(55 \%)$ & $24(60 \%)$ & \\
\hline Basic & $6(15 \%)$ & $4(10 \%)$ & \\
\hline \multicolumn{3}{|l|}{ Occupation } & \multirow{3}{*}{0.464} \\
\hline Employee & $10(25 \%)$ & $14(35 \%)$ & \\
\hline Not Employee & $30(75 \%)$ & $26(65 \%)$ & \\
\hline \multicolumn{4}{|l|}{ Medical data } \\
\hline Diabetes mellitus & $23(57.5 \%)$ & $22(55 \%)$ & 0.967 \\
\hline Hypertension & $18(45 \%)$ & $16(40 \%)$ & 0.863 \\
\hline Heart disease & $10(25 \%)$ & $13(32.5 \%)$ & 0.676 \\
\hline Liver diseases & $1(2.5 \%)$ & $1(2.5 \%)$ & -- \\
\hline
\end{tabular}

Chi-square test

Table (2): Preoperative symptoms of BPH of study and control groups (N.80).

\begin{tabular}{|c|c|c|c|}
\hline \multirow[b]{2}{*}{ Main symptoms } & \multicolumn{2}{|c|}{ Group } & \multirow[b]{2}{*}{ p-value } \\
\hline & $\begin{array}{c}\text { Study } \\
\text { N. }=40(\%)\end{array}$ & $\begin{array}{c}\text { Control } \\
\text { N. }=40(\%)\end{array}$ & \\
\hline Difficulty starting urination & $20(50 \%)$ & $25(62.5 \%)$ & \multirow{8}{*}{0.971} \\
\hline Interrupted stream & $22(55 \%)$ & $23(57.5 \%)$ & \\
\hline Terminal dribbling & $30(75 \%)$ & $29(72.5 \%)$ & \\
\hline Inability to completely empty the bladder & $27(67.5 \%)$ & $28(70 \%)$ & \\
\hline Urgency & $10(25 \%)$ & $9(22.5 \%)$ & \\
\hline Increased urinary frequency & $7(17.5 \%)$ & $6(15 \%)$ & \\
\hline Burning micturition & $10(25 \%)$ & $9(22.5 \%)$ & \\
\hline Hematuria & $1(2.5 \%)$ & $1(2.5 \%)$ & \\
\hline
\end{tabular}

Chi-square test 
Total pre test knowledge level (P. value 0.621)

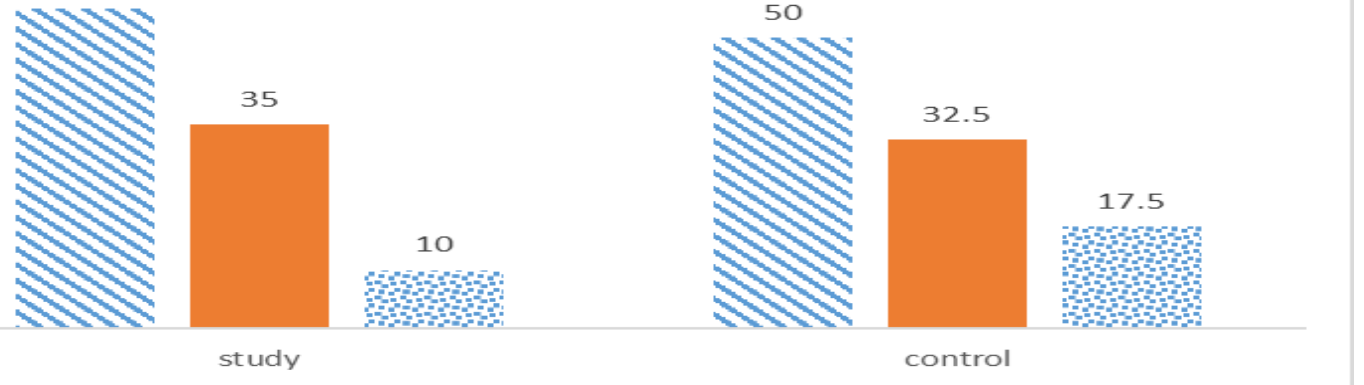

Fig (1): Total pretest knowledge level among study and control groups.

Table (3): Comparison between the total level of knowledge post-application of pre-operative nursing instructions among study and control groups (N.80).

\begin{tabular}{|l|c|c|c|}
\hline \multirow{2}{*}{ Total knowledge } & \multicolumn{2}{c|}{ Groups } & \multirow{2}{*}{ p.value } \\
\cline { 2 - 3 } & Study & Control & \multirow{2}{*}{$0.001^{*}$} \\
\hline Good (satisfactory) & $30(75 \%)$ & $7(17.5 \%)$ & \\
\hline Fair & $8(20 \%)$ & $13(32.5 \%)$ & \\
\hline Poor & $2(5 \%)$ & $20(50 \%)$ & \\
\hline Mean \pm SD & $16 \pm 3.2$ & $9 \pm 0.7$ & \\
\hline
\end{tabular}

Chi-square test \&one-way-Annova test

Table (4): Distribution of postoperative complications between study and control groups (N.80).

\begin{tabular}{|c|c|c|c|}
\hline \multirow[b]{2}{*}{ Complications } & \multicolumn{2}{|c|}{ Groups } & \multirow[b]{2}{*}{ p.value } \\
\hline & $\begin{array}{c}\text { Study } \\
\text { N. }=\mathbf{4 0}(\%)\end{array}$ & $\begin{array}{c}\text { Control } \\
\text { N. }=40(\%)\end{array}$ & \\
\hline Hematuria & $20(.625 \%)$ & $25(62.5 \%)$ & $0.001 *$ \\
\hline UTI & $8(20 \%)$ & $10(25 \%)$ & $0.044 *$ \\
\hline Urine out flow obstruction & $5(12.5 \%)$ & $2(5 \%)$ & 0.220 \\
\hline Weak urine stream & $5(12.5 \%)$ & $2(5 \%)$ & 0.182 \\
\hline Urine incontinence & $2(5 \%)$ & $1(2.5 \%)$ & 0.220 \\
\hline
\end{tabular}

Chi-square test

Table (5): Relation between patients' knowledge levels after application of nursing instructions (study and control groups) about TURP and their demographic characteristics (N.80).

\begin{tabular}{|c|c|c|c|c|c|}
\hline \multirow{2}{*}{\multicolumn{2}{|c|}{ Demographic characteristics }} & \multicolumn{3}{|c|}{ Posttest knowledge level (study group) } & \multirow{4}{*}{$\begin{array}{r}\text { p.value } \\
0.456\end{array}$} \\
\hline & & \multirow{3}{*}{$\begin{array}{c}\begin{array}{c}\text { Poor } \\
\mathbf{2}(\mathbf{5} \%)\end{array} \\
0(0.0 \%) \\
2(5 \%)\end{array}$} & \multirow{2}{*}{$\begin{array}{c}\begin{array}{c}\text { Fair } \\
\mathbf{8}(\mathbf{2 0 \%})\end{array} \\
0(0.0 \%) \\
\end{array}$} & \multirow{2}{*}{$\begin{array}{c}\begin{array}{c}\text { Satisfactory } \\
\mathbf{3 0}(\mathbf{7 5 \%} \%)\end{array} \\
2(5 \%) \\
\end{array}$} & \\
\hline & 40-50 years & & & & \\
\hline Age & $50-65$ years & & $8(20 \%)$ & $28(70 \%)$ & \\
\hline \multirow{4}{*}{ Marital Status } & Single & $0(0.0 \%)$ & $2(5 \%)$ & $0(0.0 \%)$ & \multirow{4}{*}{$0.001^{*}$} \\
\hline & Married & $0(0.0 \%)$ & $3(7.5 \%)$ & $24(60 \%)$ & \\
\hline & Divorced & $0(0.0 \%)$ & $3(7.5 \%)$ & $0(0.0 \%)$ & \\
\hline & Widow & $2(5 \%)$ & $0(0.0 \%)$ & $6(15 \%)$ & \\
\hline \multirow{3}{*}{ Level of education } & Illiterate & $2(5 \%)$ & $1(2.5 \%)$ & $9(17.5 \%)$ & \multirow{3}{*}{$0.001 *$} \\
\hline & read and write & $0(0.0 \%)$ & $1(2.5 \%)$ & $21(52.5 \%)$ & \\
\hline & Basic & $0(0.0 \%)$ & $6(15 \%)$ & $0(0.0 \%)$ & \\
\hline \multirow{2}{*}{ Occupational status } & Employee & $0(0.0 \%)$ & $4(10 \%)$ & $6(15 \%)$ & \multirow{2}{*}{0.110} \\
\hline & Not Employee & $2(5 \%)$ & $4(10 \%)$ & $24(60 \%)$ & \\
\hline
\end{tabular}

Chi-square test 


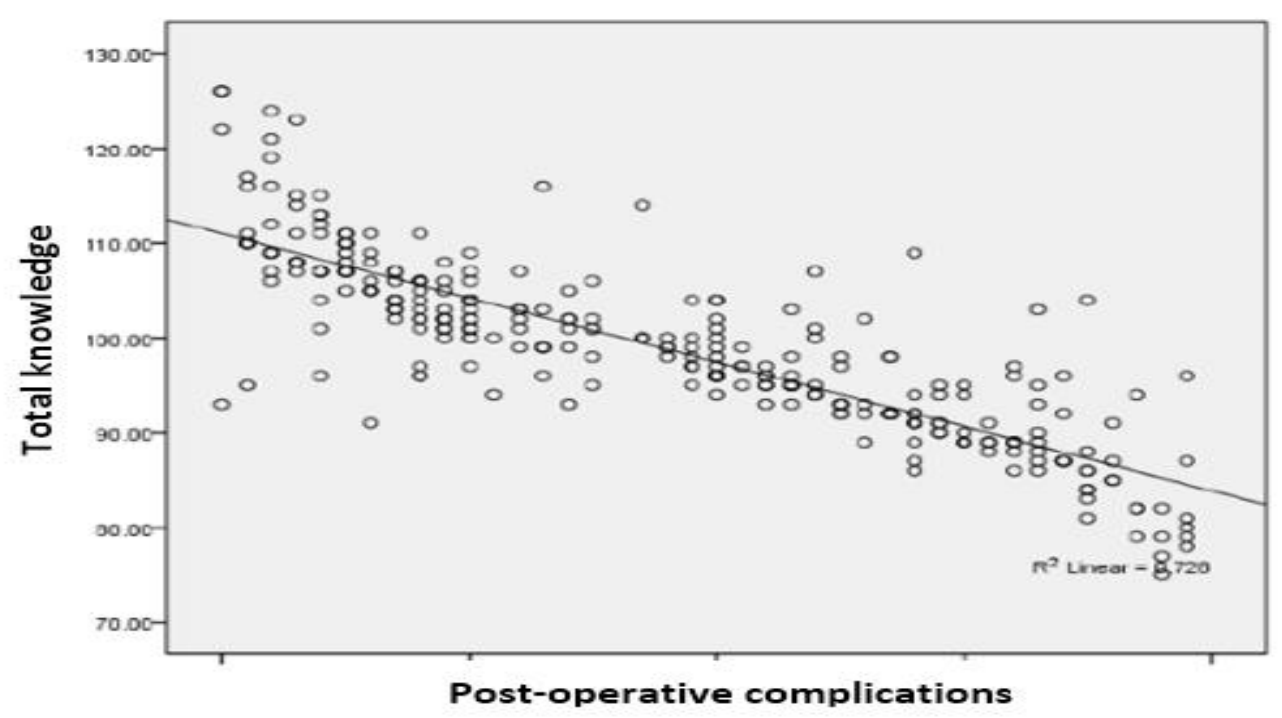

Fig (2): Correlation between postoperative complications and post-test of the total knowledge scores among the study group

Demographic data are presented in table (1): revealed that the age of the majority of the patients in both study and control groups $(95 \%$ and $92.5 \%$ respectively) and was between 50-65years old for study and control groups. It was found that more than two-thirds of patients in both groups were married (67.5\% and $82.5 \%$ respectively). Regarding the level of education, more than half of the study and control group were read and write $(55 \% \%$ and $60 \%$ respectively). There was no statistically significant difference between both groups regarding their demographic characteristics. Diabetes Mellitus wares the most common associated co-morbidity.

Table (2): Show that the main pre-operative symptoms were terminal dribbling and inability to empty the bladder (75\% and $67.5 \%)$ among the study group and $(72.5 \%$ and $70 \%)$ respectively.

Fig (1): Show that there was no statistically significant difference between the study and control group regarding their knowledge level about TURP.

Table (3): Show that there was a significant difference between the study and control group regarding their knowledge level about TURP after the application of the pre-operative instructions most of the study group have a satisfactory knowledge level $(75 \%)$ and half of the control group have a poor knowledge level (50\%).

Table (4): Shows that there was no statistically significant difference between study and control groups regarding postoperative complications after application of nursing instructions except hematuria and UTI, which were the major postoperative complications.
Table (5): Shows that there was no significant statistical difference between patients' knowledge in the post-test (among the study and control groups) about TURP and their demographic characteristics except regarding the educational level and marital status.

Fig (2): Shows that there was a negative correlation between postoperative complications and total knowledge score of the post-test among the study group with $(\mathrm{P}=0.001 *$ and $\mathrm{r} .=-0.720)$ which mean when patient knowledge increase the postoperative complications after TURP reduce.

\section{Discussion:}

Transurethral resection of the prostate (TURP) considers the golden treatment of benign prostatic hyperplasia (BPH) (Chughtai et al., 2016).

This study aimed to evaluate the effect of preoperative nursing instructions on the patients' knowledge and potential post-operative complications of TURP.

The discussion will cover the study finding regarding: Socio-demographic characteristics of the studied patients:

It was observed that was no significant difference between the study and control groups considering their demographic data. This considers a positive point for this research to avoid bias through homogeneity between the study and control groups regarding their characteristics.

In this study majority of patients in both groups their ages within average adulthood, that finding was like other studies where the patient's ages were between 
50 to 65 years old. This is due to the underlying disease.

From the researcher opinion (BPH) is considered an age-related condition described by histological changes of the prostate stromal and glandular tissue showing expanded expansion rate around the urethra, bringing about the prostatic extension, and expanded stromal smooth tone.

Also, the study finding matched with (Xu et al., 2018) who found that bladder obstruction and lower urinary tract symptoms are common in benign prostatic hyperplasia. This is similar to the finding of a study done by Leibbrand, et al., (2019) who added that the incidence of benign prostatic hyperplasia is among $50 \%$ of men aged from 50 to 60 years old and rises with increasing age.

Also, Bagla et al., (2017) found that the ages of hyperplasic patients treated with TURP were from 40 to less than 60 years old.

Signs and symptoms of BPH:

The present study showed that; there was no statistically significant difference between the study and control groups regarding their signs and symptoms of BPH. Most of the patients of the study were emergency cases presented by terminal dribbling. A common obstruction symptom among old males is due to $\mathrm{BPH}$.

From the researcher opinion enlarged prostate compromise the urethral opining that cause obstruction symptoms.

Furthermore, McVary et al., (2019) finding not match the present study's findings. As they found that the overstimulation of the smooth muscle tone through $\alpha$-adrenergic receptors can worsen the obstruction symptoms, resulting in urine retention and decreasing of the urinary flow rate.

Alexander et al., (2019) found that patients with an enlarged prostate experience difficulty in passing urine. This because of the compresses of the enlarged prostate on the urinary tube coming from the bladder. One option for treatment of this condition is telescopic surgery, which acts to remove prostate tissue and relieve the blockage.

Indications for operative management of BPH include recurrent urinary tract infection (UTI) caused by bladder outlet obstruction, recurrent episodes of urinary retention, bladder calculi, recurrent hematuria caused by bladder outlet obstruction, and renal insufficiency caused by BPH. Bladder calculi may not be the absolute indication for prostatic surgery after ESWL because only a small number of patients needed that (Huang et al., 2017).

\section{Patients' knowledge regarding TURP:}

The current study reported that; there was a statistically significant difference regarding patients' level of knowledge about TURP, between pre and post-application of the pre-operative nursing instructions among the study group. Our results showed that most of the patients did not know the correct knowledge before the application of the preoperative nursing instructions, which indicates that the patient did not receive enough information from the health care team.

From the researcher opinion it's important to patient to know all about his illness and it has effect on patient outcome.

This finding could be attributed to the insufficient educational services at the primary care facilities and their low literacy skills (Applegate et al., 2020).

In developing countries, there is a deficiency in the resources that may hinder the implementation of high-quality surgical and healthcare services to those groups of patients.

Also, when the patients asked about the symptoms and the complications that may result from TURB post-operative sequels, most of the patient was not aware of Certain exercises to control urine after TURP ( When can a Kegel exercise be done, and its reputation, and the most important exercises used after laparoscopic prostatectomy), also, most of the studied patients had poor knowledge, because of the demographic characteristics where the majority of patients were old age and had low-literacy levels.

This matches with Davids, \& Frenken, (2018) study who found that educational level had a great correlation with the patient's awareness toward TURB. However, Minejima et al. (2019) reported that the patients' characteristics did not correlate with the patients' level of knowledge.

However, after application of the pre-operative nursing instructions, there was a significant difference between the pre and post-test for the study group,

This was similar to the status done in other countries of similar population characteristics (Mahon \& Welliver, 2020). Also, our patients wished to have a suitable education method to receive sufficient knowledge about TURP.

This study finding was in line with Anan et al., (2020) who carried out a study to investigate the implementation of teaching programs and, they found that there was a significant increase in patients` level knowledge regarding TURP, as they found that all the studied sample were having poor knowledge, however after the application of their educational program patients level of knowledge improved.

Israël et al., (2020) found that there was a highly significant difference between patients' level of knowledge pre - post-implementation of the educational program regarding TURP surgery.

The finding of the current study agrees with Sheikh, (2019) who found that it's important to teach the patient about the diagnosis, prognosis of illness, 
treatment options, and risks associated with treatments, as the patient has the right to know all about his illness. A well-designed, comprehensive teaching plan that is based on patients' unique learning needs improves the quality of life, reduces health care costs, helps patients to reach informed decisions about their health care, and allows them to become healthier and more independent.

The present study revealed that there was no significant statistical difference between patients' level of knowledge at the post-test regarding the study and control groups about TURP, as regarded to their demographic characteristics except the educational level while the read and write patients had a high level of knowledge.

This is not matched with Ward et al., (2020) who reported that a high level of education is associated with lower post TURP complications due to awareness about the surgical procedure. While the uneducated or people with little education are ignorant about the surgical procedure.

In the current study after the application of preoperative nursing instructions, the patient's knowledge is significantly improved. This matches with $\mathbf{F u}$ et al., (2020) who reported that education is the key to successful treatment of the disease, and the nurse plays a major role as a patient educator. Patients and their families need accurate information about the disease and about the strategies to minimize its impact.

In this respect, Subrata, (2020) reported that knowledge about TURP and educational level were important positive predictors toward improving the quality of life.

Regarding postoperative complications, in this study, there was no significant difference between patients' TURP post-operative complications, except with the presence of hematuria which considers the main complication among both study and control groups plus UTI complication.

This does not match with Guo et al., (2016) who reported that the main TURP difficulties were failure to void, surgical revision, UTI, and bleeding.

It has been shown in Nurjannah et al., (2014) study that ten weeks of a cognitive-behavioral program can improve patient outcomes after TURP.

The current study finding indicating no correlation between total level of knowledge at the pretest and total complications post-application of pre-operative nursing instructions.

The researcher from his point of view explains that the previous patients' background did not affect the study results and pre-operative nursing instructions affect the patient's response and postoperative complications.
Generally, the nursing instruction had a positive effect on patients ' knowledge and decreased postoperative complications. This matches with Türk et al., (2018) who concluded that preparation of the discharge plan at home is an important duty of nurses. The discharge program ought to begin from admission, continue to the follow-up visits, and specific to the needs of the patient individually. The teaching program has positive effects on general health. In addition, it can minimize the rate of hospital readmission.

While Pisco, (2016) documented that the complications of TURP mainly bleeding, clot retention, erectile dysfunction, urinary incontinence, urethral stricture, and bladder neck contracture.

\section{Conclusion:}

Based on the results of the present study, it can be concluded that:

- There was no statistically significant difference between the study and control groups pretest regarding demographic, medical data, and patients' level of knowledge about TURP

- There was a significant improvement in the study group's total knowledge scores after the application of pre-operative nursing Instructions and postoperative complications after application of preoperative nursing instructions regarding hematuria, urethral injury, and UTI which were the major postoperative complications.

\section{Recommendations:}

- Educational booklets, handouts to teach patients and their families about how to prevent postoperative complications among patients undergoing TURP.

- Further research studies on larger populations to generalizing the study findings.

\section{References:}

- Alexander, C., Scullion, M., Omar, M., Yuan, Y., Mamoulakis, C., N'Dow, J. \& Lam, T. (2019): Bipolar versus monopolar transurethral resection of the prostate for lower urinary tract symptoms secondary to benign prostatic obstruction. Cochrane Database of Systematic Reviews, (12).78-88.

- Anan, G., Kaiho, Y., Iwamura, H., Ito, J., Kohada, Y., Mikami, J., \& Sato, M. (2020): Preoperative pelvic floor muscle exercise for early continence after holmium laser enucleation of the prostate: a randomized controlled study. BMC urology, 20(1), 3.

- Applegate, J., Ahmed, S., Harrison, M., Callaghan-Koru, J., Mousumi, M., Begum, N., \& Baqui, A. (2020): Caregiver acceptability of the guidelines for managing young infants with possible 
serious bacterial infections (PSBI) in primary care facilities in rural Bangladesh. PloS one, 15(4), e0231490

- Assiut University hospital statistical record, (2018).

- Bagla, S., Smirniotopoulos, J., Orlando, J., \& Piechowiak, R. (2017): Cost analysis of prostate artery embolization (PAE) and transurethral resection of the prostate (TURP) in the treatment of benign prostatic hyperplasia. Cardiovascular and interventional radiology, 40(11), 1694-1697.

- Cantlay, A., \& Ni Raghallaigh, H., (2015): Benign prostatic hyperplasia. InnovAiT, 8(4), P.P. 238-245

- Chughtai B., Forde J., Thomas D., Laor, L., Hossack T., Woo H., \& Kaplan S., (2016): Benign prostatic hyperplasia. Nature Reviews Disease Primers, 2, P.P. 16031

- D'Ancona, C., Haylen, B., Oelke, M., Abranche L., Arnold, E., Goldman, H., \& Schizas, A. (2019): The International Continence Society (ICS) report on the terminology for adult male lower urinary tract and pelvic floor symptoms and dysfunction. Neurourology and urodynamics, 38(2), P.P. 433-477

- Davids, M., \& Frenken, K. (2018): Proximity, knowledge base and the innovation process: Towards an integrated framework. Regional Studies, 52(1), 23-34

- Fu, M., Kurnat-Thoma, E., Starkweather, A., Henderson, W., Cashion, A., Williams, J., \& Calzone, K. (2020): Precision health: A nursing perspective. International journal of nursing sciences, 7(1), 5-12

- Guo, R., Yu, W., Meng, Y., Zhang, K., Xu, B., Xiao, Y., \& Pan, B. (2016): Correlation of ASA grade and the Charlson comorbidity index with complications in patients after transurethral resection of the prostate. Urology, 98, 120-125.

- Huang, W., Cao, J., Cao, M., Wu, H., Yang, Y. Y., Xu, Z., \& Jin, X. (2017): Risk factors for bladder calculi in patients with benign prostatic hyperplasia. Medicine, 96(32).

- Israël, B., van der Leest, M., Sedelaar, M., Padhani, A., Zámecnik, P., \& Barentsz, J. (2020). Multiparametric magnetic resonance imaging for the detection of clinically significant prostate cancer: what urologists need to know. Part 2: interpretation. European urology, 77(4), 469-480

- Kassouf, W., Aprikian, A., Black, P., Kulkarni, G., Izawa, J., Eapen, L., \& Sridhar, S. (2016): Recommendations for the improvement of bladder cancer quality of care in Canada: A consensus document reviewed and endorsed by Bladder Cancer Canada (BCC), Canadian Urologic Oncology Group (CUOG), and Canadian Urological
Association (CUA), Canadian Urological

Association Journal, 10(1-2), P.P. E46

- Leibbrand, M., Siefer, S., Schön, C., Perrinjaquet-Moccetti, T., Kompek, A., Csernich, A., \& Kreuter, M. (2019): Effects of an oil-free hydroethanolic pumpkin seed extract on symptom frequency and severity in men with benign prostatic hyperplasia: a pilot study in humans. Journal of medicinal food, 22(6), 551-559.

- Levett, D., Edwards, M., Grocott, M., \& Mythen, M., (2016): Preparing the patient for surgery to improve outcomes. Best practice \&research clinical anesthesiology, 30(2), 145-157.

- Mahon, J., \& Welliver, C. (2020): National Trends in the Management of Lower Urinary Tract Symptoms Associated with Benign Prostatic Hyperplasia. Current Urology Reports, 21(12), 1-6.

- Mamoulakis, C., Efthimiou, I., Kazoulis, S ., Christoulakis, I., \& Sofras, F., (2011): The modified Clavien classification system: a standardized platform for reporting complications in transurethral resection of the prostate World J Urol (2011) 29:205-210

- Martin-Plank, L., (2018): Urological and Gynecological Disorders. Advanced Practice Nursing in the Care of Older Adults, P.P. 280.

- McVary KT, Roehrborn CG, Avins AL, Barry MJ, Bruskewitz RC, \& Donnell RF, (2019): Update on AUA guideline on the management of benign prostatic hyperplasia. J Urol;185:17931803.

- Minejima E, Lee E, Quach S, Santos N, Lou M, \& Wong-Beringer A (2019): Understanding patient perceptions and attitudes toward urinary tract infections and treatment in a medically underserved population. Journal of the American College of Clinical Pharmacy, Vol. (2), No. (6): Pp. 616-622.

- Moschini, M., Stabile, A., Mattei, A., Montorsi, F., Cathelineau, X., \& Sanchez-Salas, R., (2019): Enhanced recovery after surgery (ERAS) in radical cystectomy patients: from consensus to evidence, P.P. 345:355

- Nurjannah, I.; Mills, J.; Usher, K.; \& Park, T (2014): Discharge planning in mental health care: An integrative review of the literature. J. Clin. Nurs. 23, 1175-1185.

- Pisco JM, (2016): Medium- and long-term outcome of prostate artery embolization for patients with benign prostatic hyperplasia: results in 630 patients. J Vasc Intvent Radiol. 27:1115-22.

- Scardino, P., \& Kelman, J. (2010): Dr. Peter Scardino's Prostate Book, Revised Edition: The Complete Guide to Overcoming Prostate Cancer, Prostatitis, and BPH. Penguin.p.p.345:355. 
- Sheikh, D. (2019): Outcome of Chronic Suppurative Otitis Media Surgery In Two Teaching Hospitals In Kenya.9-52.

- Silva-Smith, K. (2017): Management of Common Illnesses, Diseases, and Health Conditions. Gerontological Nursing Competencies for Care, P.P. 305.

- Subrata, S. (2020): Health-related quality of life in patients undergoing TURP: Translating evidence into urological nursing practice. International Journal of Urological Nursing, 14(1), 36-46

- Thompson S. (1992): The use of statistical significance tests in research: Source criticisms and Alternatives. Paper presented at the annual meeting of the American Educational Research Association, San Francisco.

- Türk, H., Ün, S., \& Arslan, E. (2018): A new surgical technique: transvesical resection of prostate-case series. International Braz j Urol, 44(5), 1023-1031.

- Urological Sciences Research Foundation, (2011): Volume 170, January, P.P. 172-176.

- Ward, T., Skubic, M., Rantz, M., \& Vorderstrasse, A. (2020): Human-centered approaches that integrate sensor technology across the lifespan: Opportunities and challenges. Nursing Outlook.44

- World Medical Association (2013): World medical association declaration of Helsinki; Ethical principles for medical research involving human subjects. JAMA, Vol. (310), No. (20): Pp. 21912194.

- Xu, P., Xu, A., Chen, B., Zheng, S., Xu, Y., Li, H., \& Liu, C. (2018): Bipolar transurethral enucleation and resection of the prostate: Whether it is ready to supersede TURP?. Asian journal of urology, 5(1), 48-54. 